\title{
Effect of Molasses Addition Level to the Mixture of Calf Starter and Corn Fodder on Pellet Quality, Rumen Development and Performance of Holstein-Friesian Calves in Indonesia
}

\author{
Sri Mukodiningsih ${ }^{1}$, S. P. S. Budhi ${ }^{2}$, A. Agus ${ }^{2}$, Haryadi $^{3}$ and Sang Jip Ohh ${ }^{4}$ \\ ${ }^{1}$ Dept. of Animal Nutrition, Diponegoro University, Semarang-Indonesia, ${ }^{2}$ Dept. of Animal Nutrition, \\ ${ }^{3}$ Dept. Food Technology, Gadjah Mada University, Indonesia, \\ ${ }^{4}$ College of Animal Life Sciences, Kangwon National University, Korea
}

\begin{abstract}
Effect of molasses addition to complete calf starter(CCS) and the following pellet processing was evaluated with 12 HolsteinFriesian (HF) calves (7-14 d old with $42 \pm 5.5 \mathrm{~kg}$ average BW), with 6 calves (replicate) per treatment. The CCS was formulated with $65 \%$ concentrate calf starter and 35\% local corn fodder. On the CCS, molasses was added either 5\% (M5) or 10\% (M10), then the mixture was pelleted and fed to the calves for 7 weeks. Molasses addition, regardless of addition level, improved $(p<0.05)$ both the durability and hardness of the pellet which contains $35 \%$ of high fibrous local corn fodder. Upon feeding to calves, the feed intake and daily gain were numerically higher with $5 \%$ molasses addition compared to $10 \%$ molasses addition. Blood VFA level was remarkably higher $(\mathrm{p}<0.01)$ in calves fed M10 than calves fed M5. There was no difference (p>0.05) in blood glucose level between M5 and M10. Length and number of papillae were not different ( $\mathrm{p}>0.05)$ by the addition levels of molasses. However, there was one exception in number of papillae at caudo-dorsal sac which were higher $(\mathrm{p}<0.05)$ number in M5 than M10 calves. Considering the quality of CCS pellet, calf performance and rumen development, there was no additional benefit of $10 \%$ molasses addition compared to $5 \%$. From the results of this study, 5\% molasses addition could be recommended for local farmer when they utilize local corn fodder to make CCS for HF calves in Indonesia.
\end{abstract}

(Key words : Molasses, Complete calf starter, Pellet quality, Rumen development, Holstein-Friesian calves)

\section{INTRODUCTION}

Good quality calf starter needs to contain both grain and good quality forage to be physically suitable for the development of reticulo-rumen (Baldwin et al., 2004). Grain or other readily available carbohydrate (RAC) in rumen is fermented and known to produce volatile fatty acid (VFA), especially propionate and butyrate that can stimulate papillary development (Lane et al., 2000). On the other hand, hay and forage are given to calves as fiber sources that could stimulate muscular development of the reticulo rumen (Suarez et al, 2007). This means calves should be provided with not only adequate amount of fibrous feed but also that of RAC (Morisse et al., 2000). Therefore, a balanced combination of both grain and fiber sources has been feed formulator's concern to make a good quality complete calf starter (CCS).

In Indonesia, feeding calf starter made of poor quality fiber source has been a local practice that needs to be changed. This kind of poor feeding practice has retarded the development of rumen, therefore retarded growth of calves as well as their weaning age (ranging 3-6 months). For this reason, it has been a desire for the local farmer to have a good quality CCS made of cheaper local fiber source. But good quality forage has been very limited and seasonally varied.

Indonesian local corn fodder production is about 11 million tons (DM) per year and have been evaluated more beneficial for cattle than conventional rice straw. Most of corn fodder has been utilized as roughage for adult ruminant, whereas little has been used for young ruminant. Although corn fodder is inferior to typical hay or forage, it contains about 56\% NDF (DM). Therefore, use of corn fodder as a NDF source for calves, has been suggested as a texture feed to stimulate rumen development. Feeding value of the corn fodder for Holstein-Friesian (HF) calves was once evaluated better than rice straw (Sri Mukodiningsih et al., 2008). They

* Corresponding author: Sang Jip Ohh, College of Animal Life Sciences, Kangwon National University, Korea. Tel: +82-33-250-8631, Fax: +82-33-255-5482, E-mail: sjohh@kangwon.ac.kr 
found a combination of $65 \%$ calf starter and $35 \%$ corn fodder mash as the best ratio for pre weaning (2-9 wks) HF calves.

However, relatively poor palatability and reduced intake have been a problem of corn fodder to substitute good quality forage. In addition, fine particles in mash calf starter also caused negative impact on intake and performance of calves, whereas pelleted calf starter was positive on intake (Quigley, 2001b). Average daily intake tended to be higher with pelleted starter than mash starter for 3-6 weeks calves (Ghorbani et al., 2007). Dry matter intake of complete calf starter that contained 25\% starch but 50\% NDF from barley straw was not decreased once pelleted (Morisse et al., 2000). These finding, suggests pelleting could maintain the intake of complete calf starter even if it was incorporated with poor quality forages.

The pellet quality (hardness and durability) is known to be primarily affected by the characteristics of ingredient (Thomas, et al., 1998; Cavalcanti and Behnke, 2005). Since high fiber ingredient has been mostly problematic to make a good quality pellet, it has been difficult to pellet CCS due to higher amount of fiber. Therefore, it is needed to use a binder ingredient to make durable pellet with high fiber mash. Molasses has been used not only as a binder ingredient for pelleting, but also as a palatability enhancer for calf starter (Morales et al, 1989; Quigley, 2001b). However, there is a scarcity of information on how much molasses could be suitable for pelleting CCS with high NDF content.

In addition, the molasses was also known to stimulate calf rumen development (Lensmeister and Heinrichs, 2005). But little is known how much molasses could be appropriate for the rumen development. Typical CCS has been generally formulated with 5-8\% molasses (as fed basis) (Fischer et al., 2008). If this level was increased to $12 \%$, it further improved the palatability and decreased the dust of calf starter (Morales et al., 1989). In another report (Lensmeister and Heinrichs, 2005), however, up to $12 \%$ molasses was not suggested because it could decrease feed intake and daily gain. This means it is still not clear how much molasses addition could be appropriate for CCS pellet. Therefore, molasses addition to make a good quality CCS pellet needs to be assessed not only by feed intake but also by rumen functioning and development.

This study was executed to know the appropriate molasses addition level to the mixture of concentrate calf starter and corn fodder to make a good quality CCS pellet in view of pellet quality, growth performance and rumen development of Holstein Friesian calves.

\section{MATERIALS AND METHODS}

\section{Preparation of experimental diet}

Two levels (v/w) of molasses, 5\%(M5) and 10\% (M10) were compared to find the practically appropriate addition level of molasses to the complete calf starter (CCS). Since it has been well established (Lesmeister and Heinrichs, 2005; Mentschel et al, 2001) that the molasses addition to calf diet have stimulated the rumen development via VFA production, this study did not set $0 \%$ molasses negative control but focus on finding the effective addition level of the molasses. Nutrients composition of concentrate calf starter, local corn fodder and cane molasses is shown in Table 1. Crude protein, crude fiber, and starch were analyzed according to the AOAC method (1990), and NDF according to Van Soest method (1994). Calf starter was formulated to meet the nutrient requirement of calves (NRC, 2001) with 18\% protein and 75\% TDN. Then the CCS was formulated with 65\% calf starter and $35 \%$ local corn fodder meal (Table 1). Corn fodder used in this study was harvested at early milk stage and sun dried until having about 13\% moisture. The dried corn fodder was then ground by hammer mill equipped with $3 \mathrm{~mm}$ screen. To the CCS, either 5\% molasses (DM, v/w) (M5) or 10\% molasses (DM, v/w) (M10) were added, then the mixture of CCS and molasses were pelleted. Molasses used in this study was a feed grade cane molasses purchased from local feed dealer. Formula and nutrients composition of both M5 and M10 CCS is shown in Table 2.

Table 1. Nutrient composition of calf starter, corn fodder and cane molasses

\begin{tabular}{lccc}
\hline Nutrients (\%, DM) & Calf starter & Corn fodder & Cane \\
\hline \hline Crude Protein & 18.81 & 9.96 & 3.50 \\
NDF & 10.75 & 66.97 & 0.0 \\
Crude fiber & 0.90 & 25.78 & 0.0 \\
TDN & 78.49 & 56.90 & 75.00 \\
Starch & 33.15 & 21.79 & 0.0 \\
Sugars & 36.83 & 24.21 & 47.20 \\
Calcium & 0.94 & 0.50 & 0.57 \\
Phosphorus & 0.60 & 0.36 & 0.10 \\
\hline
\end{tabular}

1) Adopted from NRC (2001). 
Table 2. Formula and nutrient composition of experimental complete calf starter

\begin{tabular}{lrc}
\hline \multirow{2}{*}{$\begin{array}{l}\text { Ingredients and } \\
\text { Nutrient Content }\end{array}$} & \multicolumn{2}{c}{ Molasses addition levels (\%) } \\
\cline { 2 - 3 } Ingredients (\%) & & 10 (M10) \\
Ground yellow corn & 25.00 & 23.70 \\
Rice bran & 17.00 & 16.15 \\
Soybean meal & 17.50 & 16.60 \\
Molasses & 5.00 & 10.00 \\
Min premix* & 0.50 & 0.50 \\
Corn fodder & 35.00 & 33.15 \\
\hline Total & 100.00 & 100.00 \\
\hline Nutrient Content (\%, DM) & & \\
Crude Protein & 16.18 & 15.55 \\
NDF & 30.99 & 30.22 \\
Crude fiber & 9.15 & 8.73 \\
TDN & 71.60 & 71.64 \\
Starch & 30.40 & 28.37 \\
Sugars & 32.74 & 33.54 \\
Calcium (Ca) & 0.83 & 0.80 \\
Phosphorus (P) & 0.56 & 0.52 \\
\hline
\end{tabular}

* Min premix provided the following (g per $\mathrm{kg}$ of diet): $\mathrm{CaCO}_{3}$ : 2.5; $\mathrm{Ca}_{2} \mathrm{PO}_{4}$ : 1.25; $\mathrm{Mn}$ : 0.0175; I: 0.01; K: 0.005; $\mathrm{Cu}: 0.0075$; $\mathrm{NaCl}: 1.15$; Fe: 0.04 ; $\mathrm{Zn}: 0.01$ and $\mathrm{Mg}: 0.0075$.

\section{Pelleting process}

Before pelleting, all the ingredients were carefully ground by hammer mill (Rabda Co., Indonesia) with $3 \mathrm{~mm}$ screen to get coarse but appropriate particles for pelleting. The ground ingredients were mixed and the molasses was sprayed during mixing. This molasses added mash was steam conditioned at $75-80^{\circ} \mathrm{C}$ for about 15 seconds. Final moisture content and temperature of conditioned mash was $16-18 \%$, and $60-65^{\circ} \mathrm{C}$, respectively. Pelleting was done with an extruder pellet mill (Rabda Co., Indonesia), equipped with flat die with $6 \mathrm{~mm}$ die holes. Pellet durability was measured with modified KSU (Kansas State University, USA) tumbling can method (ASAE, 1997) and hardness of pellet was measured with spring hardness tester.

\section{Feeding trial}

Feeding trial was done for 7 weeks, employing 12 Holstein Friesian (HF) calves (7-14 days old with $42 \pm 5.5 \mathrm{~kg}$ average initial body weight). Amount of milk and CCS allowances were calculated by the NRC equation (NRC,
2001) after measuring body weight of each calves every week. Based on the calculated need of energy and protein, both CCS and milk were prepared in the ratio of 4:6 and were given twice a day at 7:00 AM and 3:00 PM. The starter feed was given $30 \mathrm{~min}$ after giving milk (Morisse et al., 2000). Water was also provided ad libitum and changed twice a day (Lesmeister and Heinrichs, 2005). Twelve calves were allotted by the randomized block design for feeding trial with two treatments and 6 calves per treatment. Two dietary treatments were; 5\% molasses added CCS pellet (M5) and 10\% molasses added CCS pellet (M10). Individual feed intake and daily gain of each calf were measured every week. Both blood VFA and glucose concentrations were measured at wk 2 and 6 during feeding period. About $10 \mathrm{ml}$ of blood samples were individually collected at 3 hours after 7:00 AM feeding via jugular venipuncture using evacuated vacuum tube. Total blood VFA concentration was analyzed using GLC and blood glucose concentration using glucose oxidase-peroxidase 4 aminophenazone-phenol (GOD-PAP) methods (Quigley et al., 1991).

\section{Morphological rumen development}

To compare rumen development, 4 male calves (2 calves per treatment) were slaughtered at the end of feeding trial. Whole digestive tracts were harvested, emptied, and rinsed with cold water, then transported immediately to the laboratory for the following rumen dissection and tissue sampling according to the procedure (Lesmeister et al., 2004). Three rumen tissue samples per each location were collected from 3 different locations (cranial sac, caudo ventral blind sac and caudo dorsal sac). The samples were embedded in paraffin, sectioned, then stained with hematoxylin and eosin (Anonymous, 1957) for visual inspection under light microscope (Nikon YS 100, Japan). Both length (cm) and number of rumen papillae at each location were measured and photomicrograph for the representative specimen was taken using microscope camera (Olympus DP 12, Japan).

\section{Statistical analysis}

Data of the experiment were analyzed by ANOVA using GLM procedure of SAS (SAS institute. Inc., Cary, NC). Data of blood VFA and glucose concentration were evaluated using split plot design and then t-tested if significant (Still and Torrie, 1981). 


\section{RESULTS AND DISCUSSION}

\section{Physical quality of CCS pellet}

Physical quality of pellet is shown in Table 3. Both durability and hardness of the CCS pellet were improved $(\mathrm{p}<0.05)$ by molasses addition. Addition of $10 \%$ molasses produced more $(\mathrm{p}<0.05)$ durable $(98.85 \%$ vs. $95.84 \%)$ and harder $\left(4.80 \mathrm{~kg} / \mathrm{cm}^{2}\right.$ vs. $\left.4.27 \mathrm{~kg} / \mathrm{cm}^{2}, \mathrm{p}<0.05\right)$ pellet than $5 \%$ molasses addition, respectively. Improvement of pellet physical quality by molasses addition was also previously confirmed (Thomas et al., 1998). Since starch content of M5 diet was higher than that of M10, degree of starch effect as a pellet binder could not be higher in M10. Therefore, the improved pellet quality in M10 presumed to be induced by sugars from additional molasses. Since Parker (1988) recommended $\sim 4.5 \mathrm{~kg} / \mathrm{cm}^{2}$ hardness and higher than $90 \%$ durability as a borderline of good quality pellet with $5 \mathrm{~mm}$ diameter, both 5 and $10 \%$ molasses addition in this study were satisfactory for improving durability and hardness quality of CCS pellet incorporating corn fodder.

\section{Performance of calves}

The result of feeding trial is summarized in Table 4. It indicated that adding extra molasses did not result in an extra beneficial effect on daily CCS intake and average daily gain (ADG). The dry matter CCS intake was not different between $5 \%$ and $10 \%$ molasses additions. Since molasses was known to improve the palatability of calf starter, with more magnitude for a feed incorporated with poor quality forage such as corn fodder in this experiment, $10 \%$ molasses was expected to induce an increased feed intake. In addition, pelleting of CCS was also expected to increase the feed intake as reported in other study (Yuangklang et al., 2005). But M10 did not exert further benefit on both feed intake and following growth response. Since the pellet of both M10 and M5 were durable and hard enough to induce (Table 3), condensed and increased intake, extra palatability effect could not be a factor in this study.

There was no additional benefit on ADG by $10 \%$ molasses addition compared to 5\% (552 g/day for M5 and $535 \mathrm{~g} /$ day for M10) in the current study. Lesmeister and Heinrichs (2005) used molasses up to $12 \%$ in calf starter and found it had decreased both dry matter intake and average daily gain. Daily feed intake of M10 (80 g/calf) was also numerically
Table 3. Effect of molasses addition on physical quality of pellet

\begin{tabular}{|c|c|c|c|c|}
\hline \multirow{2}{*}{$\begin{array}{l}\text { Pellet Quality } \\
\text { Parameters }\end{array}$} & \multirow[b]{2}{*}{$\mathrm{n}$} & \multicolumn{2}{|c|}{$\begin{array}{c}\text { Molasses addition levels } \\
(\%)\end{array}$} & \multirow{2}{*}{$\begin{array}{l}\text { Pellet without } \\
\text { molasses } \\
\text { addition* }\end{array}$} \\
\hline & & 5 (M5) & 10 (M10) & \\
\hline Hardness $\left(\mathrm{kg} / \mathrm{cm}^{2}\right)$ & 12 & $4.27 \pm 0.27^{b}$ & $4.80 \pm 0.24^{\mathrm{a}}$ & $3.98 \pm 0.33^{\mathrm{C}}$ \\
\hline Durability (\%) & 12 & $95.84 \pm 1.89^{\circ}$ & $98.85 \pm 1.78^{\mathrm{b}}$ & $95.49 \pm 2.01^{\mathrm{a}}$ \\
\hline
\end{tabular}

${ }^{\mathrm{abc}}$ Mean values \pm SD with different superscripts in the same row are significantly different $(\mathrm{p}<0.05)$

* As a reference for this table, both hardness and durability were simultaneously measured for pellet without $(0 \%)$ molasses addition.

Table 4. Effect of dietary molasses addition on performance of Holstein Friesian calves

\begin{tabular}{|c|c|c|c|}
\hline \multirow{2}{*}{ Parameters } & \multirow[t]{2}{*}{$\mathrm{n}$} & \multicolumn{2}{|c|}{$\begin{array}{c}\text { Molasses addition } \\
\text { levels (\%) }\end{array}$} \\
\hline & & 5 (M5) & 10 (M10) \\
\hline Average initial body wt. (kg/calf) & 12 & $42.90 \pm 2.07$ & $42.00 \pm 2.07$ \\
\hline Average body wt at 8 wk (kg/calf)* & 12 & $70.50 \pm 3.50$ & $68.75 \pm 3.10$ \\
\hline Daily CCS intake (DM g/calf)* & 12 & $85 \pm 3.17$ & $80 \pm 2.55$ \\
\hline Average daily gain (g/calf)* & 12 & $552 \pm 54.58$ & $535 \pm 41.85$ \\
\hline
\end{tabular}

lower than that of M5 (85 g/calf) in this study. This study also confirmed that $10 \%$ molasses addition to calf starter is not beneficial for HF calves although the CCS was incorporated with rather poor quality local corn fodder.

\section{Changes in blood profile}

Total blood VFA (BVFA) concentrations were affected by diet and age of calves. BVFA was significantly $(\mathrm{p}<0.01)$ higher in M10 than M5 at 6 wk (Table 5), although dry matter intake was similar between M10 and M5. Readily available carbohydrate (RAC) in molasses was proposed as fermentable energy for rumen to produce VFA (Murphy, 1999; Quigley, 2001a). Higher molasses, in fact, resulted in the increase of rumen VFA (Sahoo et al., 1999; Araba et al., 2002) and numerical increase in BVFA (Lesmeister and Heinrichs, 2005).

It has known that the VFA is strongly responsible for stimulating papillae development (Baldwin and Jesse, 1992) in young ruminant that has function to absorb VFA. Therefore, the calf starter which is capable to generate more VFA is proposed as a promoter of rumen papillae development. Among VFA, butyrate has been most effective for increasing 
Table 5. Effect of dietary molasses addition on blood VFA and glucose concentrations in HolsteinFriesian calves

\begin{tabular}{lcccc}
\hline \multirow{2}{*}{$\begin{array}{l}\text { Blood } \\
\text { Parameters }\end{array}$} & $\begin{array}{c}\text { Age } \\
\text { (week) }\end{array}$ & & \multicolumn{2}{c}{ Molasses addition levels (\%) } \\
\cline { 5 - 6 } \cline { 4 - 5 } & 2 & 12 & $0.030 \pm 0.014^{\mathrm{a}}$ & $0.033 \pm 0.021^{\mathrm{a}}$ \\
VFA (mmol/L) & 6 & 12 & $0.393 \pm 0.005^{\mathrm{Ab}}$ & $0.944 \pm 0.001^{\mathrm{Bb}}$ \\
\hline \multirow{2}{*}{ Glucose (mg/dl)* $^{*}$} & 2 & 12 & $71.5 \pm 1.43$ & $72.2 \pm 2.01$ \\
& 6 & 12 & $72.6 \pm 1.97$ & $73.2 \pm 2.03$ \\
\hline
\end{tabular}

${ }^{\mathrm{AB}} \mathrm{VFA}$ values $\pm \mathrm{SD}$ with different capital superscripts in the same row are significantly different $(\mathrm{p}<0.01)$

${ }^{\mathrm{ab}}$ VFA values \pm SD with different superscripts in the same column are significantly different $(\mathrm{p}<0.01)$

* There were no $(\mathrm{p}>0.05)$ statistical differences in glucose level between M5 and M10.

both size and number of papillae (Lane et al., 2000; Mentschel et al., 2001; Zitnan et al., 2003). These well developed papillae enable more VFA absorption, in turn, to the blood of pre weaning calf (Quigley, 2001a). This has been a background how the blood level of VFA became an indicator criterion of ruminal development. M10 had generated more VFA compared to M5 in this study, which is similar to other result (Lesmeister and Heinrichs, 2005). Therefore, the appropriate molasses supplementation level in the view of an appropriate VFA generation became an interesting question since too much VFA were reported not beneficial for rumen development (Lesmeister and Heinrichs, 2005; Suarez et al, 2006).

BVFA concentrations were significantly changed $(p<0.05)$ by the age of calves. Blood VFA in 6 weeks-old HF calves was higher than that in 2 weeks old. This result indicated that there would be no microbial fermentation of feed and VFA production and subsequently no VFA absorption in 2 weeks old HF calves. When calves are first born, the rumen is sterile and there are no bacteria, therefore, it has little muscular activity and little rumen function as well (Behar ka et al., 1998; Quigley, 2001a). Then, if calves are fed milk, hay, and grain from shortly after birth, normal rumen contraction can be measured at as early as wk 3 of age (Quigley, 2001a). This explains how 6 wk calves in this study were capable to absorb more VFA compared to 2 wk calves. This also could be the reason why Suarez et al. (2006) recommended calves to access solid feed as early as possible during 3-8 weeks transition period.

There were no differences in blood glucose concentration between M5 and M10 calves. Since M10 diet contains more sugar from molasses than M5, it is speculated that the more sugar could be fermented to produce more VFA, which was shown as an increase in blood VFA concentration by M10 diet. Although Lee et al. (2008) evaluated calf starter containing $1 \%$ molasses and reported the blood glucose concentration had decreased with age from wk 2 to wk 6, there is no such an age associated decrease in this study. Since the glucose is known as the main energy source for neonatal calf until the rumen is developed to produce sufficient amount of VFA (Quigley, 2001a), it is predicted the blood glucose level could be decreased with age. However, there have been also other reports (Ilgaza et al, 2003; Stanley et al, 2005; and Biljana et al, 2007) that found no significant difference in blood glucose with increasing age up to 8 weeks. And those results about blood glucose were similar to the result of this study.

This study, therefore, showed that 5\% dietary molasses could be considered satisfactory in the view of blood VFA generation which is able to result proper rumen development in $\mathrm{HF}$ calves fed complete calf starter incorporating corn fodder as structural forage.

\section{Rumen Development}

Length and number of papillae at three different sac of rumen were measured to estimate the degree of rumen development. Length and numbers of papillae are shown in Table 6, and their photomicrographs in Fig. 1. There were no significant differences in papillae number and length between M5 and M10 calves. Only the number of papillae at caudo-dorsal sac was exceptionally higher $(\mathrm{P}<0.05)$ in $\mathrm{M} 5$ than in M10 calves. Length of papillae in this study was within the normal range as previously reported (Suarez et al., 2007). Papillae length in cranial sac was longer than that in dorsal sac, which is also similar to the previous report (Beharka et al., 1998).

There was no physical and morphological difference between M5 and M10 on rumen papillae although M10 diet caused more branching on rumen papillae in cranial and caudo-dorsal sacs as shown in Fig. 1. Higher VFA was proposed (Suarez et al., 2006; Bannink et al, 2008) as a possible stimulator to increase the surface area of rumen epithelium by branching of the papillae. This study also exerted more VFA production by higher molasses (Table 5). But Lesmeister and Heinrichs (2005) reported that extra 
Table 6. Effect of dietary molasses addition on length and number of rumen papillae of Holstein Friesian calves at $7 \mathrm{wk}$

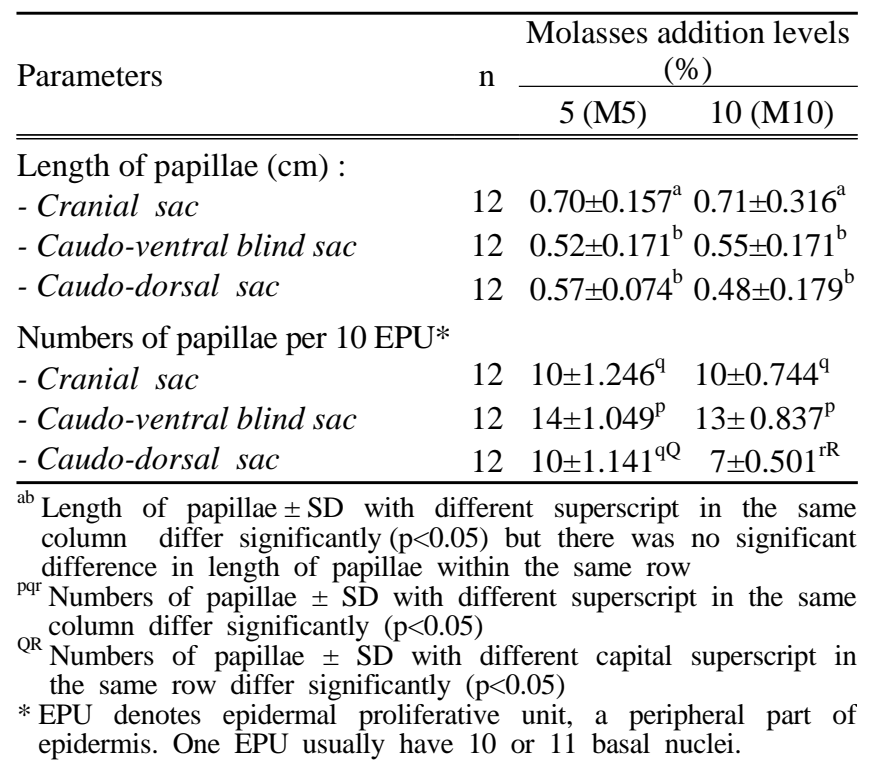

molasses $(12 \% \mathrm{DM})$ in calf starter resulted only a numerical increase of papillae length compared to control (5\% DM) molasses level. The current study also confirms there is no additional advantage of $10 \%$ molasses addition in view of papillae length and numbers.

Therefore, it is difficult to explain why there was no additional VFA effect on rumen development in this study. Araba et al. (2002) reported that propionate proportion decreased with increasing dietary molasses level. Since the propionate is primarily needed to stimulate rumen papillae development (Baldwin and Jesse, 1992), it could explain why there was no beneficial effect with more VFA. In addition, Suarez et al. (2006) suggested the higher RAC could induce ruminal acidosis and subsequently damaged rumen mucosa development. Since more molasses generated more RAC, it could be the reason why there was no benefit of $10 \%$ molasses on rumen development in this study. Therefore, it is suggested that $5 \%$ molasses addition could be sufficient
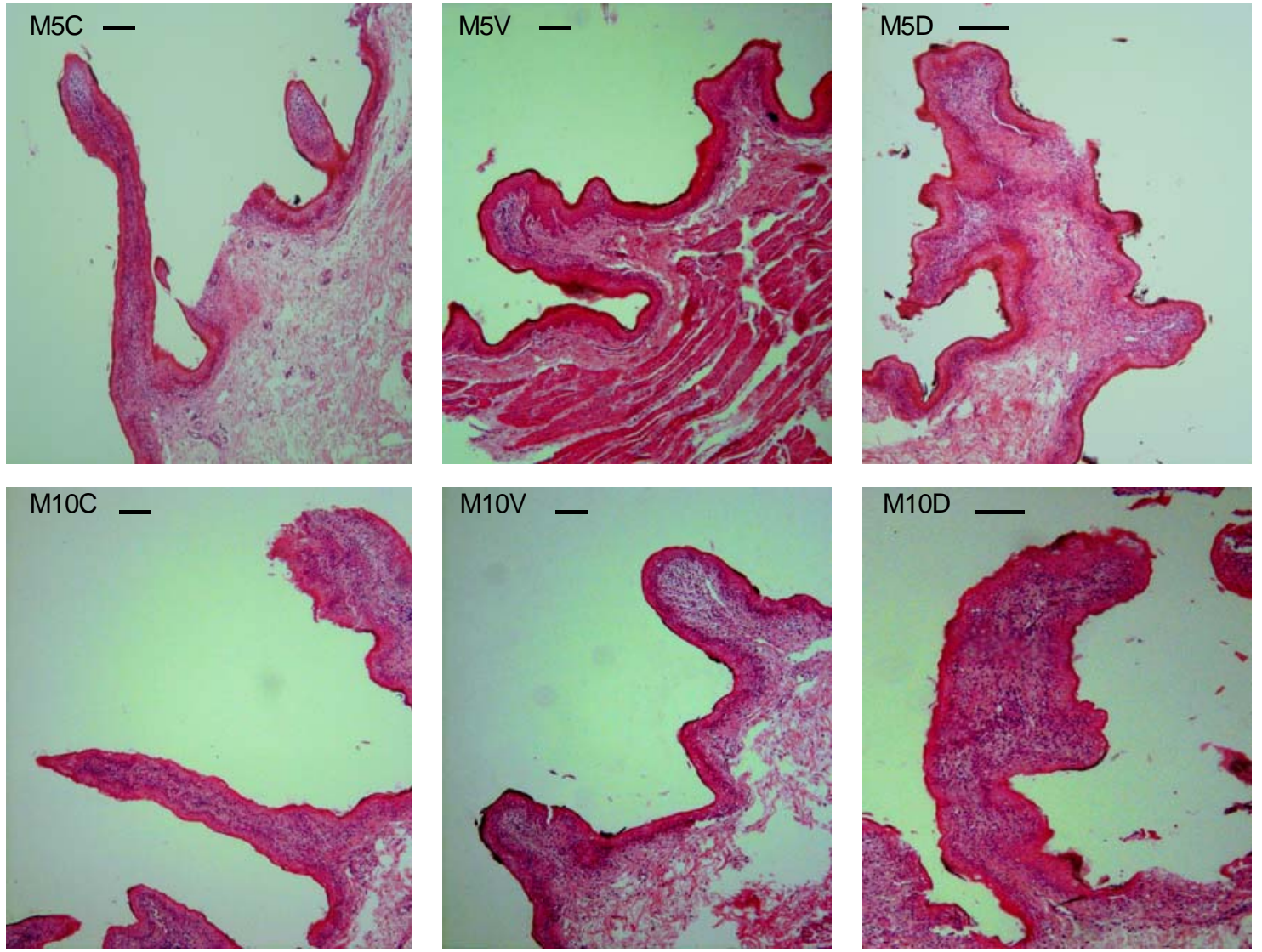

Fig. 1. Photomicrographs of rumen papillae $(n=36)$ of 7 wk Holstein-Friesian dairy calves.

M5 and M10 denote dietary molasses addition levels 5 and 10\%, respectively. C, V and D respectively denote cranial sac, caudo-ventral blind sac and caudo-dorsal sac of rumen. Solid bars ( - ) on each photomicrograph are indicating 1 $\mathrm{mm}$ length. Although there were no remarkable differences in length and shape of papillae by the level of dietary molasses, 10\% (M10) molasses induce more branching on papillae in both cranial and caudo-dorsal sacs. 
enough for the proper rumen development when feeding a CCS pellet diet, incorporated with local corn fodder in Indonesia.

\section{IMPLICATION}

To make a good quality complete calf starter by incorporating a substantial amount of poor quality local corn fodder in Indonesia, $5 \%$ molasses addition can be recommended since $5 \%$ molasses was sufficient enough to produce good quality CCS pellet, to improve gain and to stimulate rumen development in Holstein-Friesian calves. Relatively higher (10\% in this study) level molasses addition does not exert additional benefit in views of performance and rumen development.

\section{REFERENCES}

Anonymous 1957. Manual of Histologic and Special Staining Technics. Armed Forces Institute of Pathology. General Pathology Laboratory, Washington, D.C.

Araba, A., Byers, F. M. and Guessous, F. 2002. Patterns of rumen fermentation in bulls fed barley/molasses diets. Anim. Feed Sci. and Tech. 97:53-64.

AOAC. 1990. Official Methods of Analysis. $15^{\text {th }}$ ed. Association of Official Analytical Chemists. Arlington, VA.

ASAE. 1997. ASAE S319.2, Method of determining and expressing fineness of feed materials by sieving. Standards, 1997. Am. Soc. Agric. Eng., St. Joseph, MI

Baldwin, R. L. VI and Jesse, B. W. 1992. Development changes in glucose and butyrate metabolism by isolated sheep ruminal cells. J. Nutr. 122:1149-1153.

Baldwin, R. L., VI, McLeod, K. R., Klotz, J. L. and Heltmann, R. N. 2004. Rumen development, intestinal growth and hepatic metabolism in the pre- and post weaning ruminant. J. Dairy Sci. 87:(Suppl.):E55-E65.

Bannink, A., France, J., Lopez, S., Gerrits, W. J. J., Kebreab, E., Tamminga, S. and Dijkstra, J. 2008. Modeling the implications of feeding strategy on rumen fermentation and functioning of the rumen wall. Anim. Feed Sci. and Tech. 143(1-4):3-26.

Beharka, A. A., Nagaraja, T. G., Morrill, J. L., Kennedy, G. A. and Klemm, R. D. 1998. Effects of form of the diet on anatomical, microbial, and fermentative development of the rumen of neonatal calves. J. Dairy Sci. 81:1946-1955.

Biljana, R., Samanc, H. and Ivana, P. 2007. Concentration of cortisol, insulin and lipids in the blood of calves at various ages. Acta. Vet.(Beograd) 57:191-198.

Cavalcanti, W. B. and Behnke, K. C. 2005. Effect of composition of feed model systems on pellet quality: a mixture experimental approach II. Cereal Chem. 82, 462-467.

Fischer, D., Heinrichs, A. and Chester-Jones, H. 2008. http://www. extension.org/faq/25216

Ghorbani, G.. R., Bagheri Varzaneh, M. and Nikkhah, A. 2007. Comparison of traditional ground and commercial pelleted starters for pre weaning Holstein calves. Int. J. Dairy Sci. 72: 2331-2338.

Ilgaza, A. and Birgele, E. 2003. Dynamics of glucose in postnatal ontogenesis in calves in association with age and feed. Vet. Zootech. T 21:74-77

Lane, M. A., Baldwin, R. L. and Jesse, B. W. 2000. Sheep rumen metabolic development in response to different dietary treatments. J. Anim. Sci. 78:1990-1996.

Lee, H. J., Khan, M. A., Lee, W. S., Kim, H. S., Ki, K. S., Kang, S. J., Hur, T. Y., Khan, M. S. and Choi, Y. J. 2008. Growth, blood metabolites, and health of Holstein calves fed milk replacer containing different amounts of energy and protein. Asian-Aus. J. Anim. Sci. 21:198-203.

Lesmeister, K. E., Tozer, P. R. and Heinrichs, A. J. 2004. Development and analysis of a rumen tissue sampling procedure. J. Dairy Sci. 87:1336-1344.

Lesmeister, K. E. and Heinrichs, A. J. 2005. Effect of adding extra molasses to texturized calf starter on rumen development, growth characteristics, and blood parameters in neonatal dairy calves. J. Dairy Sci. 88:411-418.

Mentschel, J., Leiser, R., Mulling, C., Pfarrer, C. and Claus, R. 2001. Butyric acid stimulates rumen mucosa development in the calf mainly by a reduction of apoptosis. Arch. Anim. Nutr. 55:85-102.

Morales, J. L., Van Horn, H. H. and Moore. J. E. 1989. Dietary interaction of cane molasses with source of roughage: Intake and lactation effects. J. Dairy Sci. 72:2331-2338.

Morisse, J. P., Huonnic, D., Cotte, J. P. and dan Martrenchar, A. 2000. The effect of four fibrous feed supplementations on different welfare traits in veal calves. Anim. Feed Sci. and Tech. 84:129-136.

Murphy, J. J. 1999. The effect of increasing the proportion of molasses in the diet of milking dairy cows on milk production and composition. Anim. Feed Sci. and Tech. 78:89-198.

NRC. 2001. Nutrient Requirements of Dairy Cattle, $7^{\text {th }}$ rev. ed. National Res. Council. National Academy Press. Washington, DC.

Parker, J. 1988. Pelleting Hand Book. California Pellet Mill, Ltd., 
Singapore.

Quigley, J. D. 2001a. Development of the rumen epithelium. Calf Note \#20. Available from URL: http:// www. calfnotes.com.

Quigley, J. D. 2001b. Palatability of calf starter. Calf Note \#47. Available from URL: http://www.calfnotes.com.

Quigley, J, III, Caldwell, L. A., Sinks, G. D. and Heitmann, R. N. 1991. Changes in the blood glucose, non-esterified fatty acids, and ketones in response to weaning and feed intake in young calves. J. Dairy Sci. 74:250-257.

Sahoo, A., Agarwal, N., Kamra, D. N., Chaudhary, L. C. and Pathak, N. N. 1999. Influence of the level molasses in deoiled rice bran-based concentrate mixture on rumen fermentation pattern in crossbred cattle calves. Anim. Feed Sci. and Tech. 80:83-99.

Sri Mukodiningsih., S. P. S. Budhi., A. Agus and Haryadi. 2008.

Effect of variation of protein and neutral detergent fiber sources in complete calf starter on the development indicator of reticulo rumen. J. Ind. Trop. Anim. Agr, 33:132-138.

Stanley, C., Williams, C., Jenny, B., Fernandez, J., Bateman, H., Nipper, W., Lovejoy, J., Gantt, D. and Goodier, G. 2002. Effects of feeding milk replacer once versus twice daily on glucose metabolism in Holstein and Jersey calves. J. Dairy Sci. 85:2335-2343.

Steel, R. G. D. and Torrie, J. H. 1981. Principle and Procedures of Statistic. 2nd ed. McGraw-Hill International Book Company,
New York.

Suarez, B. J., Van Reenen, C. G., Stockhofe, N., Dijkstra, J. and Gerrits, W. J. J. 2007. Effect of roughage source and roughage to concentrate ratio on animal performance and rumen development in veal calves. J Dairy Sci. 90:2390-2303.

Suarez, B. J., Van Reenen, C. G., Gerrits, W. J. J., Stockhofe, N., Van Vuuren, A. M. and Dijkstra, J. 2006. Effects of supplementing concentrates differing in carbohydrate composition in veal calf diets: II. Rumen development. J. Dairy Sci. 89: 4376-4386.

Thomas, M., van Vliet, T. and van der Poel, A. F. B. 1998. Physical quality of pelleted animal feeds. 3. Contribution of feedstuff components. Anim. Feed Sci. and Tech. 70:59-78.

Van Soest, P. J. 1994. Nutritional Ecology of the Ruminant. ISBN 0-9601586-0 O\&B Books, Inc. Corvalis, Oregon.

Yuangklang, C., Wanapat, M. and Wachirapakorn, C. 2005. Effects of pelleted sugarcane tops on voluntary feed intake, digestibility and rumen fermentation in beef cattle. Asian Aus. J. Anim. Sci. 18:22-26.

Zitnan, R., Kuhla, S., Nurnbuerg, K., Schonhunsen, U., Ceresnakova, Z., Sommer, A., Baran, A., Greserova, G. and Voigt, J. 2003. Influence of diet on the morphology of ruminal and intestinal mucosa and on intestinal carbohydrate levels in cattle. Vet. Med. 48:177-182.

(Received May 13, 2010; Revised June 4, 2010; Accepted June 15, 2010) 